\title{
State Medicaid Programs Bring Managed Care Tenets to Fee for Service
}

\author{
Shellie L. Keast, PharmD, PhD; Grant Skrepnek, PhD; and Nancy Nesser, PharmD, JD
}

\begin{abstract}
SUMMARY
Rising numbers of enrollees in state Medicaid programs have resulted in the increased use of commercial managed care organizations by the states. Research shows that the implementation of these programs has produced mixed results. While many states have implemented managed care principles and have seen reductions in costs, some basic managed care tenets may not apply to a Medicaid population because of limited financial risk and responsibility. The application of commercial managed care organizations to these populations may not result in additional savings for those states already actively engaged in managed care. As such, the purpose of this article is to provide a synopsis of key managed care principles as applied to state Medicaid programs and discuss issues regarding the optimization of cost, access, and quality for this population.
\end{abstract}

J Manag Care Spec Pharm. 2016;22(2):145-48

Copyright $\odot 2016$, Academy of Managed Care Pharmacy. All rights reserved.

$\mathrm{T}$ he last decade has seen an increase in the number of state Medicaid programs relying on commercial managed care companies as a way to lower costs while promoting effective health care for their members. ${ }^{1-3}$ Fueled in part by the passing of the Affordable Care Act (ACA) and by the increased Medicaid membership following the recent fiscal crisis, states are seeking to lower the costs of health care for their low-income citizens, while still providing quality care and access. Fee-for-service (FFS) programs are generally seen as providing fragmented and uncoordinated care, whereas the coordinated care models of managed care may reduce wasteful or duplicative spending. ${ }^{4}$ Because of Medicaid expansion under the ACA, states are looking for ways to shift risk away from government agencies and towards market-based providers. ${ }^{5}$ While the ACA Medicaid expansion started in 2014, many states started moving to managed care delivery models much earlier, with several large programs moving to commercial managed care organizations (MCOs) in 2011. ${ }^{5}$

The concept of managed care is not new to Medicaid programs, where many variations have been adopted, ranging from partially capitated plans run by the state to fully capitated managed care contracts with outside commercial vendors., ${ }^{1,6}$ By 2010 , it was reported that $70 \%$ of Medicaid enrollees were in some type of managed care structure, yet only $20 \%$ of the total Medicaid expenditures went to contracted commercial MCOs. ${ }^{1}$ States choose to try risk-based managed care for various reasons, such as reducing cost, budget predictability, or to improve access to care. At this time, 38 states and the District of Columbia are engaged in risk-based agreements. ${ }^{7}$ One-half of all Medicaid beneficiaries nationwide are enrolled in riskbased managed care plans.

Historically, commercial managed care participation was limited to pregnant women, children, and parents, with the more chronically ill remaining in the FFS environment. This may have resulted in the low total expenditures covered by MCOs in the past, ${ }^{1}$ but these plans are now beginning to include members with complex health needs, such as those in long-term care facilities. ${ }^{7}$ If the move to commercial MCOs is in response to increased pressure to manage costs, excluding the highest cost patients seems counterproductive. Thus, recent trends indicate that states are beginning to enroll their more chronically ill patients into MCO programs. ${ }^{8}$ But, before this trend can be fully understood, an exploration of the basic differences between managed care and FFS and their influence on Medicaid programs is warranted.

\section{Traditional Fee for Service}

As the population began to shift from self-pay for health care services to third-party payer systems (i.e., where an insurance company pays for services for the patient), the traditional FFS model, or indemnity insurance, was born. Although frequently used interchangeably, ${ }^{9}$ a stricter definition of indemnity insurance indicates repayment of health care costs to the patient by the insurer, while FFS consists of payment to the providers directly (e.g., Blue Cross was one of the first and largest payers of this type).$^{10}$ In the most basic FFS model, contracts are signed between the payer and provider; prices are set; services are rendered to the patient and billed to the insurer; and finally, payment is sent from the insurer to the health care provider. There is no management or determination of need (defined by the payer) for the service before its provision: If a covered service is involved, then payment is made up to the allowable amount, less any portion for which the patient is responsible. Adaptations to this basic model include additional controls such as prior authorization by the payer of medical services and prescription products before service is rendered.

Basic FFS may be perceived as a relatively simple model to execute, although the potential for excess use does exist, including waste and misuse, especially as prices increase and complex health care services are developed and performed. ${ }^{4}$ Examples of potential overuse, or moral hazard, on behalf of the patient may include a shift in demand for additional diagnostic testing or interventions, which may ultimately increase expenditures or inefficiencies more than would be expected through normal economic principals.,11 From the 
provider perspective, a shift in demand toward more profitable diagnostics or interventions may also emerge, which is an issue articulated within the Goddeeris Model. ${ }^{12}$ Given these concerns, alternate models that include managed care have been proposed and implemented (noting that third-party coverage in itself may involve incentives that can shift the demand of either the patient or provider in economically inefficient ways). ${ }^{13,14}$

In January 2015, the U.S. Department of Health and Human Services (HHS) announced its intent to shift payment away from FFS models to value-based models..$^{15}$ As part of this shift, HHS has set specific goals: $30 \%$ of FFS Medicare payments should be tied to quality by 2016 ; this percentage would increase to $50 \%$ by 2018 . While the FFS model was not designed to deal with today's complex health environment and high-cost service and products, newer models have yet to be thoroughly vetted and evaluated in terms of cost-effectiveness. The managed care model was born out of a need to optimize cost, access, and quality. As such, what are the attributes that define the managed care model?

\section{The Managed Care Model}

In his 2009 book, Managed Care Pharmacy Practice, Robert Navarro lists 3 basic tenets of managed care: (1) "it is a subscription" with a contract defining benefits and premium costs to the sponsor and to individuals; (2) all "stakeholders and participants" are "financially and contractually linked," which ensures financial risk as well as control of use of services; and (3) costs are managed by "controlling the supply and demand of healthcare resources." ${ }^{\prime 6}$ This definition works well for the commercially insured population (by way of either employer or self-purchase). Once this principal is applied to a Medicaid program, however, numerous challenges are presented. First, while a Medicaid program may indeed contract with a commercial vendor and satisfy part of the first tenet, there is no mechanism to reach back to the enrollee, since, by definition, this beneficiary does not typically possess the same level of financial responsibility required for a monthly premium payment.

Likewise, for the second tenet, there may be minimal financial linkage between the Medicaid program and the enrollee, who may have little vested interest in reducing the already minimal out-of-pocket costs that are limited under federal law and thus does not share in the financial risk or have incentive to limit services. Similarly, it may be difficult for the commercial vendor to maximize the third tenet by the usual patient cost-sharing means. When a Medicaid program contracts with a commercial managed care vendor, the basic tenets of managed care are therefore only met superficially between the state Medicaid program and the MCO. Therein, when considering differences between theoretical principals of insurance, the concept of moral hazard is unique for the previously uninsured or very low-income population.

Moral hazard suggests that consumers of health care may purchase more services once they become insured than they would have if paying for all services themselves. ${ }^{17}$ The price for health care services approaches $\$ 0$ for those enrolled in Medicaid and could result in increased use of unnecessary services, along with a high income transfer (in this case from the taxpayer to the Medicaid enrollee). This income transfer is in the form of taxes paid to the state and federal governments, which are used to fund the public programs. ${ }^{13,18-20}$ The welfare loss in this case is transferred to the government payers and, ultimately, the taxpayer. While this does not necessarily suggest that commercial vendors cannot manage a Medicaid population effectively, it may indicate that this population requires a unique type of managed care.

\section{Managed Care in Medicaid: Are We Optimizing Costs,} Access, and Quality?

While a few reports have been issued regarding this topic, robust assessments are currently lacking., ${ }^{1,3,8,21,22}$ A report by the Lewin Group in 2004 indicated that states' savings when utilizing MCOs ranged from 2\% to 19\%. ${ }^{3}$ Differences in savings also hinge on whether the plan is for profit or not for profit, with for-profit plans potentially having lower quality, and whether the plan includes the adult disabled population. ${ }^{21,22}$ In a 2012 publication, Iglehart proposed that a key advantage of Medicaid MCOs was the trade-off in risk from the state to the MCO because of the capitated rates. ${ }^{8}$ Finally, a 2012 report by the Robert Wood Johnson Foundation stated that nationally there was little savings to be had in switching to a commercial MCO and that the evidence was lacking on whether quality was improved. ${ }^{1}$ This report further indicated that policymakers should be cautious when considering the potential benefits of commercial Medicaid managed care programs. Many of the reasons given are based on those already discussed here, including limited risk-sharing transferrals to individual enrollees and the programs that states have implemented, as discussed below.

While most state Medicaid programs have been operating on an assumed FFS model, in reality much has been done to mirror components of the managed care model, with adaptations for low risk-sharing for enrollees. ${ }^{1}$ For example, 33 states have implemented various forms of primary care/case management (PCCM) programs where the primary care provider (PCP) is the home base for the member's medical care. ${ }^{1}$ Several states have a patient-centered medical home model of care delivery. ${ }^{23,24}$ In both of these models, the PCP provides case management and referral to specialty care. The PCPs are typically paid a small monthly case management fee in addition to FFS payments for specific services. Preliminary review of these models indicated mixed results, with most results being favorable clinically, while less favorable on costs. ${ }^{23}$ By the end of 2015, all but 5 states had implemented, or planned to implement, a new delivery system model such as an MCO or PCCM. ${ }^{25}$ At least half of the states have also created disease management and care management programs to assist members with chronic care needs. ${ }^{26,27}$ 
States have also implemented utilization controls in the form of prior authorization for service or limitations on quantity or duration of services, particularly in pharmacy where all but 5 states have preferred drug lists. ${ }^{25,28}$ In states where more intensive management has occurred, when the program has been delegated to the commercial MCO, there is limited opportunity for savings, and administration costs have been suggested to be higher for some plans than for the state Medicaid agency. ${ }^{21}$ Therefore, the use of commercial MCOs may present unique drawbacks that include market instabilities, delivery disruptions, uninformed or confused members, and lack of ties between the MCO and the local community. ${ }^{2}$ While access issues remain for non-managed care Medicaid programs, a 2014 report by the Office of Inspector General found that managed care Medicaid enrollees were experiencing difficulties in obtaining physician appointments, as well as increased wait times. ${ }^{29}$ A major benefit of a state Medicaid program contracting with a commercial MCO may lie in the security of the first tenet offered by Navarro: the subscription. ${ }^{16}$ Thus, for a set amount, certain benefits and payments may be established and the state budget can be finalized. However, if a commercial MCO continues to include only the healthier individuals in its Medicaid plans and only accounts for a small fraction of Medicaid expenditures, there may not be a clear advantage offered.

\section{Can Fee for Service Ever Die?}

Any organization that continues to operate fully on a FFS model with no attempt to address Navarro's third tenet may ultimately continue to have excessive expenditures and waste. ${ }^{16}$ The FFS system remains challenged in today's health care system, yet all payers continue to pay providers based on some form of FFS payment system. Before FFS can truly evolve, new payment systems will have to be formed and that, in itself, remains a daunting and time-consuming task. ${ }^{30-32}$ From bundled payments to value-based systems, only robust and comprehensive methods of evaluation can establish if any of these complex arrangements or combination of systems will be able to fully replace the FFS method of payment.

\section{Management and Coordination Are Key}

As was suggested by the results from the Robert Wood Johnson report, ${ }^{1}$ for state Medicaid programs that had already been largely vested in managing the use of their enrollees, limited savings were achieved by simply switching to a different form of management. This indicates that the states which began early adaptation of managed care principles to their FFS models were able to attain similar results as those states that switched to a commercial plan before attempting any internal controls. ${ }^{1}$ Therefore, these results lend support to the claim that managed care principles were correctly applied. With regard to Navarro's third tenet, in the absence of a complete first tenet, these states were able to reduce costs. ${ }^{16}$ As self-managed states increase in knowledge and experience of the second tenet, the ability to share in financial risk with other stakeholders by developing pay-for-performance or pay-for-value programs may exist. ${ }^{16,33}$ As stated previously, many states have already developed capitated provider systems or patient-centered medical home models that further align with managed care principals. ${ }^{1}$ Again, however, scientific literature is lacking on the most effective models for managing this challenging population.

\section{Conclusions}

Policymakers should carefully weigh their options when considering converting their FFS Medicaid programs to commercial managed care vendors. For states where Navarro's third tenet has been practiced for several decades with management and care coordination programs in place, little may be achieved by converting a portion of the population to managed care. ${ }^{1,16} \mathrm{~A}$ few states have historically used commercial managed care, ultimately determining that Medicaid beneficiaries could be better managed by the state program itself. ${ }^{34,35}$ Other programs have found MCOs to be an acceptable solution. Regardless of these perspectives, the message is clear: The days of unmanaged FFS models are gone, and programs not attempting to apply managed care principles to their members may continue to experience difficulties in optimizing costs, access, and quality.

\section{Authors}

SHELLIE L. KEAST, PharmD, PhD, is Assistant Professor, and GRANT SKREPNEK, PhD, is Associate Professor, University of Oklahoma College of Pharmacy, Oklahoma City, Oklahoma. NANCY NESSER, PharmD, JD, is Pharmacy Director, SoonerCare, Oklahoma Health Care Authority, Oklahoma City, Oklahoma.

AUTHOR CORRESPONDENCE: Shellie L. Keast, PharmD, PhD, Assistant Professor, University of Oklahoma College of Pharmacy, CPB-222 P.O. Box 26901, Oklahoma City, OK 73126-0901. Tel.: 405.271.6878 x47269; Fax: 405.271.6470;

E-mail: shellie-keast@ouhsc.edu.

\section{DISCLOSURES}

Keast has provided contractual services to the Oklahoma Health Care Authority. Nesser is an employee with the Oklahoma Health Care Authority.

Concept and design for this article was primarily contributed by Keast, along with Nesser and assisted by Skrepnek. Keast took the lead in data collection, along with Skrepnek, and data interpretation was performed by Keast, Skrepnek, and Nesser. The manuscript was written primarily by Keast, with assistance from the other authors, and revised by Nesser, Keast, and Skrepnek.

\section{REFERENCES}

1. Sparer M. Medicaid managed care: costs, access, and quality of care. Research Synthesis Report No. 23. Robert Wood Johnson Foundation. September 2012. Available at: http://www.rwjf.org/content/dam/farm/ reports/reports/2012/rwjf401106. Accessed November 19, 2015. 
2. Summer L, Hoadley J. The role of medicaid managed care in health delivery system innovation. The Commonwealth Fund. April 2014. Available at: http://www.commonwealthfund.org/ /media/files/publications/fundreport/2014/apr/1741_summer_role_medicaid_managed_care_hlt_sys_ delivery.pdf. Accessed November 19, 2015.

3. The Lewin Group. Medicaid managed care cost savings—a synthesis of fourteen studies. July 2004.

4. Berwick DM, Hackbarth AD. Eliminating waste in U.S. health care. JAMA. 2012;307(14):1513-16.

5. AMCP Foundation. Ahead of the curve. Top 10 emerging health care trends: implications for patients, providers, payers and pharmaceuticals 2014. Available at: http://www.amcp.org/AMCPFoundationTrendsDoc/.

6. Hurley RE, Somers SA. Medicaid and managed care: a lasting relationship? Health Aff (Millwood). 2003;22(1):77-88.

7. Paradise J, Lyons B, Rowland D. Medicaid at 50. Kaiser Family Foundataion. May 2015. Available at: http://files.kff.org/attachment/reportmedicaid-at-50. Accessed November 19, 2015.

8. Iglehart JK. Desperately seeking savings: states shift more medicaid enrollees to managed care. Health Aff (Millwood). 2011;30(11)1627-29.

9. Gabel JR, Ginsburg PB, Whitmore HH, Pickreign JD. Withering on the vine: the decline of indemnity health insurance. Health Aff (Millwood). 2000;19(5):152-27.

10. Feldstein PJ. Health Care Economics. 6th ed. Clifton Park, NY: Thomson Delmar Learning; 2005.

11. James J. Health policy brief: Medicare hospital readmissions reduction program. Health Affairs. November 12, 2013. Available at: http://healthaffairs.org/healthpolicybriefs/brief_pdfs/healthpolicybrief_102.pdf. Accessed November 19, 2015.

12. Goddeeris JH. Medical insurance, technological change, and welfare. Econ Inq. 1984;22(1):56-67.

13. Feldstein M, Friedman B. Tax subsidies, the rational demand for insurance and the health care crisis. J Public Econ. 1977;7(2):155-78.

14. Friedman M. How to cure health care. The Public Interest. 2001;142:3-30. Available at: http://www.thepublicinterest.com/archives/200lwinter/articlel. html. Accessed November 19, 2015.

15. U.S. Department of Health and Human Services. Better, smarter, healthier: in historic announcement, HHS sets clear goals and timeline for shifting Medicare reimbursements from volume to value. January 26, 2015. Available at: http://www.hhs.gov/about/news/2015/01/26/better-smarter-healthierin-historic-announcement-hhs-sets-clear-goals-and-timeline-for-shiftingmedicare-reimbursements-from-volume-to-value.html. Accessed November 19, 2015.

16. Navarro R. Managed Care Pharmacy Practice. 2nd ed. Sudbury, MA: Jones and Bartlett Publishers; 2008.

17. Santerre RE, Neun S. Health Economics: Theory, Insights, and Industry Studies. 5th ed. Mason, OH: South-Western Cengage Learning; 2010.

18. Nyman JA. The economics of moral hazard revisited. J Health Econ. 1999;18(6):811-24.

19. Nyman JA, Maude-Griffin R.. The welfare economics of moral hazard. Int J Health Care Finance Econ. 2001;1(1):23-42.

20. Feldstein MS. The welfare loss of excess health insurance. J Polit Econ. 1973;81(2):251-80.

21. McCue MJ, Bailit MH. Assessing the financial health of Medicaid managed care plans and the quality of patient care they provide. Issue brief. The Commonwealth Fund. June 2011. Available at: http://www.commonwealthfund.org/ /media/files/publications/issue-brief/2011/jun/1511_mccue_ assessing_financial_hlt_medicaid_managed_care_plans_ib_final.pdf. Accessed Novvember 19, 2015.

22. Burns ME. Medicaid managed care and cost containment in the adult disabled population. Med Care. 2009;47(10):1069-76.
23. Peikes D, Zutshi A, Genevro J, Smith K, Parchman M, Meyers D. Early evidence on the patient-centered medical home. Final report. Prepared by Mathematica Policy Research (Contract Nos. HHSA290200900019I/ HHSA29032002T and HHSA290200900019I/HHSA29032005T). AHRQ Publication No. 12-0020-EF. Rockville, MD: Agency for Healthcare Research and Quality. February 2012. Available at: https://pcmh.ahrq.gov/sites/ default/files/attachments/Early\%20Evidence\%20on\%20the\%20PCMH\%20 2\%2028\%2012.pdf. Accessed November 19, 2015.

24. Rich E, Lipson D, Libersky J, Parchman M. Coordinating care for adults with complex care needs in the patient-centered medical home: challenges and solutions. White paper. Prepared by Mathematica Policy Research. (Contract No. HHSA290200900019I/HHSA29032005T). AHRQ Publication No. 12-0010-EF. Rockville, MD: Agency for Healthcare Research and Quality. January 2012. Available at: https://pcmh.ahrq.gov/sites/default/ files/attachments/Coordinating\%20Care\%20for\%20Adults\%20with\%20 Complex\%20Care\%20Needs.pdf. Accessed November 19, 2015.

25. Smith V, Gifford K, Ellis E, Rudowitz R, Snyder L. Medicaid in an era of health \& delivery system reform: results from a 50-state Medicaid budget survey for state fiscal years 2014 and 2015. Kaiser Family Foundation. October 14, 2014. Available at: http://files.kff.org/attachment/medicaid-inan-era-of-health-delivery-system-reform-results-from-a-50-state-medicaidbudget-survey-for-state-fiscal-years-2014-and-2015-report. Accessed November 19, 2015

26. Gillespie JL, Rossiter LF. Medicaid disease management programs: findings from three leading US state programs. Dis Manage Health Outcomes. 2003;11(6):345-61. Available at: http://www.npcnow.org/system/files/ research/download/Medicaid-DM-Programs-Findings-from-Three-LeadingUS-State-Programs.pdf. Accessed November 19, 2015.

27. Arora R, Boehm J, Chimento L, Moldawer L, Tsien C. Designing and implementing Medicaid disease and care management programs: a user's guide. Prepared by The Lewin Group (Contract No. 290-04-0011). AHRQ Publication No. 07-0063. Rockville, MD: Agency for Healthcare Research and Quality. March 2008. Available at: http://www.ahrq.gov/sites/default/ files/publications/files/medicaidmgmt.pdf. Accessed November 19, 2015.

28. Hoadley J. Cost Containment strategies for prescription drugs: assessing the evidence in the literature. The Kaiser Family Foundation. March 2005. Available at: https://kaiserfamilyfoundation.files.wordpress.com/2013/01/ cost-containment-strategies-for-precription-drugs-assessing-the-evidence-inthe-literature-report.pdf. Accessed November 19, 2015.

29. U.S. Department of Health and Human Services, Office of Inspector General. Access to care: provider availability in Medicaid managed care. Report No. OEI-02-13-00670. December 2014. Available at: http://oig.hhs. gov/oei/reports/oei-02-13-00670.pdf. Accessed November 19, 2015.

30. Hussey PS, Ridgely MS, Rosenthal MB. The PROMETHEUS bundled payment experiment: slow start shows problems in implementing new payment models. Health Aff (Millwood). 2011;30(11):2116-24.

31. Cunningham R. The payment reform paradox. Health Aff (Millwood). 2014:33(5):735-38.

32. Conrad D, Grembowski D, Gibbons C, et al. A report on eight earlystage state and regional projects testing value-based payment. Health Aff (Millwood). 2013;32(5):998-1006.

33. Quinn K. Achieving cost control, care coordination, and quality improvement in the Medicaid program. J Ambul Care Manage. 2010;33(1): 38-49; discussion 69-70.

34. Galewitz P. Connecticut drops insurers from Medicaid. USA Today. December 29, 2011. Available at: http://usatoday30.usatoday.com/ news/nation/story/2011-12-28/connecticut-health-care-medicare-insurance/52257962/1. Accessed November 19, 2015.

35. Johnson CS. State drops managed-care Medicaid plan for 5 counties. Billings Gazette. May 23, 2011. Available at: http://billingsgazette.com/news/ state-and-regional/montana/state-drops-managed-care-medicaid-plan-forcounties/article_aa287fc8-e435-5277-a9cd-46ad3919400b.html. Accessed November 19, 2015. 